\title{
Attachment Styles Among Bullies, Victims and Uninvolved Adolescents
}

\author{
Kristi Kõiv \\ University of Tartu, Tartu, Estonia
}

\begin{abstract}
Attachment theory provides a frame for understanding the role of attachment styles in the development of bullying behaviour in adolescence. The present study examined attachment styles (secure, avoidant and anxious/ambivalent) that differentiated bullies, victims, bully/victims and uninvolved adolescents. A total of 1,921 students (1,006 girls and 915 boys) in grades four through nine (ages 10 to 18 years old) completed a peer-reported measure (peer nomination inventory: D. G. Perry, Kusel, \& L. C. Perry, 1988) to determine the status of bullying behaviour (bullies $N=178$; victims $N=168$; and bully/victims $N=16$ ) and a self-reported measure to examine attachment style (multiple-item attachment scale: Simpson, 1990). A one-way ANOVA indicated that: (1) Bullies had higher scores in avoidant attachment scales than victims and non-participants of bullying; and (2) Victims demonstrated higher levels of insecure attachment than bullies and uninvolved adolescents. Findings reflected the role of insecure attachment as a risk factor in the development of bullying behaviour in adolescence—-bullies were at risk when their current attachment styles were avoidant and victims when their attachment styles were insecure.
\end{abstract}

Keywords: attachment theory, attachment styles, bullies, victims, bully/victims, non-participants of bullying behaviour

\section{Introduction}

Bullying among school children is a world-wide serious problem and has been extensively researched in recent decades internationally (Smith, Morita, Junger-Tas, Olweus, Catalano, \& Slee, 1999, Smith \& Brain, 2000) including Estonia (Kõiv, 2009). Bullying in school is viewed as a form of aggression involving repetition and an imbalance of power (Olweus, 1999; Smith \& Brain, 2000), and is often conceptualized along a continuum across bully category recognizing that children may be involved in bullying behavior with different degrees as the victim, a bully, a bully/victim in which they experience both and uninvolved peer (Espelage \& Swearer, 2003; Glover, Gough, Johnson, \& Cartwright, 2000). Increasing amount of research during last few years reviews the adverse concurrent and long-lasting consequences of school bullying, especially in the area of poor social adjustment in peer context (Gini \& Pozzoli, 2009; Rigby, 2003).

Attachment theory provides a fruitful theoretical background linking parental and peer relationships. The emphasis of attachment theory lies on enduring cognitive models that are carried forward into new relationships. Attachment in early life provides a foundation for future behaviors, as a child will continue to expect others to react to them on how their early caregivers did. The degree of attachment from infancy can continue to affect one's internal representation of their environment into adulthood (Bowlby, 1969; 1973). The consequence of

Kristi Kõiv, Ph.D., associate professor, Faculty of Social Science and Education, University of Tartu. 
these developmental internal representations is manifested in an individual's style of attachment, which continues throughout childhood (Main \& Cassidy, 1988) and into adolescence and adult relationships (Feeney \& Noller, 1996; C. Hendrick \& S. Hendrick, 1989). Following the pioneering works of Bowlby (1969; 1973; 1980), attachment theorists have explored the way the early attachment relationships can influence different styles marked by security, anxiety and avoidance (Collins \& Feeney, 2000). Attachment styles are relatively coherent and stable patterns of emotion and behavior that are exhibited in close relationships (Shaver, Collins, \& Clark, 1996). These early experiences can convey feelings of security and benevolence of others, and of the self as able, worthy and desirable to others. Insecure attachment can be conceptualized in categorical terms as followed from the work of Ainsworth, Blehar, Waters, and Wall (1978): ambivalent attachment-the tendency to become dependent, help-seeking, fear of abandonment and anxious/angry at separation; and avoidant attachment- the tendency to respond with withdrawal to separation, do not seek help for stress and do not have views of others as benevolent and the use of repression as a coping mechanism (Collins \& Feeney, 2000).

Several studies have documented relationships between insecure attachment in infancy and increased risk for psychopathology, aggression, antisocial and delinquent behavior in later childhood and adolescence (e.g., Fagot \& Kavanaugh, 1990; K. E. Grossmann \& K. Grossmann, 1991; Elgar, 2003; Elicker, Englund, \& Sroufe, 1992; Renken, Egeland, Marvinney, Mangelsdorf, \& Sroufe, 1989; van Ijzendoorn, 1997). A limited amount of research has looked at the relationship between bullying and victimization and attachment quality directly. Some research results in the area of children and adolescents' attachment quality to both parents and their bullying behaviors among peers are confusing.

Empirical evidence from a few studies indicated that children with insecure attachment to their mothers were more likely to bully their peers and experience more peer victimization in later childhood (Smith \& Myron-Wilson, 1998; Troy \& Sroufe, 1987). However, Monks, Smith, and Swettenham (2005) found that bullies tended to have insecure attachments, while most victims appeared to have a secure attachment.

Only few studies investigated the influence of parental attachment on peer bullying in adolescence showing that insecure parental attachment has an influence on peer bullying. Walden and Beran (2010) investigated the relationship among self-perceived bullying, victimization and material attachment quality among adolescents, finding that students who reported a high-quality attachment relationship with their primary caregiver were unlikely to bully others and be victimized. Also, Eliot and Cornell (2009) demonstrated that insecure parental attachment in middle school students was associated with both self-report and peer-report measures of bullying, reflecting the mediating relationships between insecure material attachment histories and bullying. Marini, Dane, Bosacki, and Ylc-Cura (2006) conclusions are in the same line indicating that bullies, victims and bully/victims had a lower maternal attachment than uninvolved students, with bully/victims having the lowest level of maternal attachment. Nevertheless, Coleman (2003) did not find support for the association between attachment quality and victimization (bullying was not explored): securely attached students to both parents, when compared to children who were less securely attached to both parents or children who exhibited insecure attachment, were not less likely to report being victimized.

In sum, the extent to which parent-child secure-insecure dimension of attachment quality is related to children and adolescents' involvement in perpetrating and being targeted by bullying remains unclear and evoking new research questions.

While previous research have examined the relationships between children and adolescents' attachment history and current bullying behavior, the present research addresses the question of whether or not adolescents, 
who bully others, are victimized by peers and are non-participants of bullying behavior can be distinguished by their current attachment styles.

The aim of the present study was to investigate differences of adolescents' current multidimensional attachment styles among participants and non-participants of bullying behavior.

The hypothesis was that current attachment style of the group of adolescents who are identified as bullies by peers should be more insecure compared to that of adolescents not involved in bullying behavior.

\section{Method}

\section{Participants}

A sample consist the total of 1,921 students (1,006 girls and 915 boys) in grades four through nine (ages 10 to 18 years; $M=13.1, S D=1.87$ ) from eight different randomly selected schools from Estonia.

\section{Instruments}

Multiple-item attachment scale, developed by Simpson (1990), was used to define in terms of present reports of attachment. This measure based directly on Hazan and Shaver's (1987) attachment measure indicating three paragraphs corresponding to the three attachment styles: secure, avoidant and anxious/ambivalent. The participants were asked individually to rate 13 sentences: five items for secure attachment and four items for insecure and anxious/ambivalent attachment style on a seven-point Likert scale, ranging from "strongly disagree" (1) to "strongly agree" (7). To measure each attachment style, the items corresponding to three paragraphs aggregated to form three attachment indexes, whereby higher scores reflected greater security, avoidance or anxious/ambivalent attachment style.

Peer nomination inventory (Perry, Kusel, \& Perry, 1988) was used to assess the status of bullying behavior by peer nominations. This instrument designed to enable identify peers who match particular behavior descriptions to assess bullying that contains 26 test items, including seven that measure victimization and seven measure aggressive behavior, viewing bullying as repeated aggressive behavior within the unbalanced power relationship. Pupils were requested to nominate same-sex peers who were best fitted the behavior described in each item, excluding themselves. Peer estimates were based on judgments of a greater number of children in each bully-category. From the sample, four groups were identified: bullies, victims, bully/victims (those who reported both bullying others and being bullied) and uninvolved (non-participants) in bullying behavior.

\section{Results}

School bullying of students was measured by peer nomination technique and research results indicated that $18.8 \%$ of the fourth to ninth grades $(N=362)$ students were connected with bullying: $9.3 \%$ were victims $(N=$ 178), $8.7 \%$ were bullies $(N=168)$ and $0.8 \%(N=16)$ were both bullies and victims. Eighty-one point two percent of students $(N=1,559)$ have reported as uninvolved in bullying behavior (see Table 1).

Table 1

Number and Percentage of Bullies, Victims, Bully/Victims and Uninvolved Adolescents Among the Whole Sample

\begin{tabular}{llllcc}
\hline Bullying category & Victims & Bullies & Bully/victims & Non-participants & Overall \\
\hline$N$ & 178 & 168 & 16 & 1,559 & 1,921 \\
$\%$ & 9.3 & 8.7 & 0.8 & 81.2 & 100 \\
\hline
\end{tabular}


The mean scores on the attachment measure were displayed across bully-category (victims, bullies, bully/victims and uninvolved students) in Table 2, whereby the higher scores were associated with an increased tendency to demonstrate each attachment style.

Table 2

The Mean Scores on the Three Attachment Styles Across the Status of Bullying Behavior

\begin{tabular}{|c|c|c|c|c|c|c|c|c|}
\hline \multirow[t]{2}{*}{ Attachment style } & \multicolumn{2}{|c|}{$\begin{array}{l}\text { Victims } \\
(N=178)\end{array}$} & \multicolumn{2}{|c|}{$\begin{array}{l}\text { Bullies } \\
(N=168)\end{array}$} & \multicolumn{2}{|c|}{$\begin{array}{l}\text { Bully/victims } \\
\quad(N=16)\end{array}$} & \multicolumn{2}{|c|}{$\begin{array}{l}\text { Non-participants } \\
\quad(N=1,559)\end{array}$} \\
\hline & Mean & $S D$ & Mean & $S D$ & Mean & $S D$ & Mean & $S D$ \\
\hline Secure & 4.19 & 1.25 & 4.52 & 1.33 & 4.40 & 0.98 & 4.39 & 1.19 \\
\hline Avoidant & 4.13 & 1.49 & 5.82 & 1.38 & 4.42 & 1.59 & 4.09 & 1.71 \\
\hline Anxious/ambivalent & 3.89 & 1.54 & 3.87 & 1.45 & 4.08 & 1.17 & 3.75 & 1.50 \\
\hline
\end{tabular}

One-way ANOVA's was carried out to assess bully-category (bullies, victims, bully/victims and non-participants) differences for total scores on the subscales of the multiple-item attachment scale. The results, as shown in Table 3, indicated that there were several statistically significant differences with regards to adolescents' current attachment styles and their bullying behaviors: (1) Victims reported lower secure attachment scores compared with bullies and non-involved pupils; and (2) Bullies reported higher avoidant attachment scores than victims and those who were uninvolved to bullying behavior.

Anxious/ambivalent attachment style did not differentiate significantly bullies, victims, bully/victims and uninvolved adolescents.

Table 3

F-values and P-values Comparing Different Bully-Categories on the Three Attachment Styles

\begin{tabular}{|c|c|c|c|c|c|c|c|}
\hline $\begin{array}{l}\text { Attachment } \\
\text { style }\end{array}$ & $F / p$ value & $\begin{array}{l}\text { Victim versus } \\
\text { non-participant }\end{array}$ & $\begin{array}{l}\text { Victim versus } \\
\text { bully/victim }\end{array}$ & $\begin{array}{l}\text { Victim versus } \\
\text { bully }\end{array}$ & $\begin{array}{l}\text { Bully versus } \\
\text { bully/victim }\end{array}$ & $\begin{array}{l}\text { Bully versus } \\
\text { non-participant }\end{array}$ & $\begin{array}{l}\text { Bully/victim } \\
\text { versus } \\
\text { non-participant }\end{array}$ \\
\hline \multirow{2}{*}{ Secure } & $F$ & 4.01 & 0.93 & 5.71 & 0.01 & 1.48 & 0.11 \\
\hline & $p$ & 0.05 & 0.34 & 0.02 & 0.95 & 0.22 & 0.75 \\
\hline \multirow{2}{*}{ Avoidant } & $F$ & 0.09 & 0.58 & 3.80 & 2.67 & 6.29 & 0.99 \\
\hline & $p$ & 0.76 & 0.45 & 0.05 & 0.10 & 0.01 & 0.32 \\
\hline \multirow{2}{*}{$\begin{array}{l}\text { Anxious/ } \\
\text { ambivalent }\end{array}$} & $F$ & 1.42 & 0.97 & 0.02 & 1.21 & 1.01 & 2.00 \\
\hline & $p$ & 0.23 & 0.33 & 0.90 & 0.27 & 0.32 & 0.12 \\
\hline
\end{tabular}

The hypothesis was that current attachment style of the group of adolescents who are identified as bullies by peers should be more insecure compared to that of adolescents uninvolved in bullying behavior was accepted and specified - there were significant differences in attachment styles between the three groups, with both uninvolved and victims recording significantly lower scores on the avoidant attachment scale than the bullies.

\section{Discussion}

Present attempts to understand adolescents' close relationships from the perspective of attachment have been strongly influenced by Bowlby's (1969; 1973; 1980) fundamental work on attachment and loss. Attachment theory lays the groundwork for the hypothesis that adolescents whose current attachment styles are insecure should be more likely identified as bullies by their peers. The results obtained from the research specified this prediction and indicated that bullies had higher scores in avoidant-insecure, attachment style compared with group of victims and non-participants of bullying behavior. The finding generally affirmed previous studies among children classified as avoidant type of attachment history and who most likely were 
aggressive and bully others in early and later childhood (Egeland \& Sroufe, 1981; Renken et al., 1989; Troy \& Sroufe, 1987). This finding is parallel with research results that indicated that children who bully were more likely to exhibit avoidant attachment in their adult relationships compared to those who began to bully as adults (Ireland \& Power, 2004).

On the other side, the results obtained from the research showed that attachment style of the victims of peer bullying was more insecure compared with the bullies and uninvolved students. This finding is consistent with previous research results among adolescents (Eliot \& Cornell, 2009; Marini et al., 2006; Walden \& Beran, 2010), but differed from previous studies in the measurement of attachment style. In present research, the current attachment style of the adolescents was measured, while, in previous research, it was classified in early childhood and followed through childhood and adolescence.

Overall, this study does extend to early findings that have demonstrated that children and adolescents with parental insecure attachment were more likely to be involved in bullying (Eliot \& Cornell, 2009; Marini et al., 2006; Smith \& Myron-Wilson, 1998; Troy \& Sroufe, 1987; Walden \& Beran, 2010), also showing that adolescents' current attachment styles may influence the participant role in bullying behavior: Bullies were most likely to be classified as avoidant and victims as insecurely attached. This finding drew attention to the adolescents' insecure, and especially avoidant, attachment style as a risk factor for becoming or maintaining victim-bully status in school context.

Given that the significant negative impact school bullying can have on pupils, it is important for researchers to continue examining this issue. The results of this study highlight the importance of adolescents' quality of attachment for positive peer relations in schools. The deeper understanding of the factors that are associated with bullying and victimization will better prepare teachers and specialist in schools dealing with the problem: Openly discussing with students about their roles in bullying interactions and teaching security, benevolence and trust towards others as components in comprehensive bullying prevention and intervention programs to increase attachment security.

Some limitations of the study are noted. The findings require more large samples, especially with more students identified those who reported both bullying others and being bullied. Furthermore, it should be noted that a sample with bully/victims was fewer and, therefore, the statistical power was relatively low and only the strongest effects could be detected, which may also account for the significant results. The sample was not large enough to distinguish gender or bullying type differences among adolescents' current multidimensional attachment styles. Also, used methodological approach has been used extensively in bullying and adolescent attachment research, but future research needs to use multiple sources and longitudinal design to investigate the relationship between students' quality of attachment and their status of bullying behaviour.

\section{References}

Ainsworth, M. D. S., Blehar, M., Waters, E., \& Wall, S. (1978). Patterns of attachment. Hillsdale, N. J.: Erlbaum.

Bowlby, J. (1969). Attachment and loss (Vol. 1). New York: Basic Books.

Bowlby, J. (1973). Attachment and loss (Vol. 2). New York: Basic Books.

Bowlby, J. (1977). The making and breaking of affectional bonds. British Journal of Psychiatry, 130, 201-210.

Bowlby, J. (1980). Attachment and loss (Vol. 3). New York: Basic Books.

Coleman, P. K. (2003). Perceptions of parent-child attachment, social self-efficacy and peer relationships in middle childhood. Infant and Child Development, 12, 351-368.

Collins, N. L., \& Feeney, B. C. (2000). A safe haven: An attachment theory perspective on support seeking and care giving in intimate relationships. Journal of Personality and Social Psychology, 78, 1053-1073. 
Egeland, B., \& Sroufe, L. A. (1981). Attachment and early maltreatment. Child Development, 52, 44-52.

Elgar, F. J. (2003). Attachment characteristics and behavioral problems in rural and urban juvenile delinquents. Child Psychiatry and Human Development, 34(1), 35-48.

Elicker, J., Englund, M., \& Sroufe, L. A. (1992). Predicting peer competence and peer relationships in childhood from early parent-child relationships. In R. Parke, \& G. Ladd (Eds.), Family-peer relations: Models of linkage (pp. 77-106). Hillsdale, N. J.: Erlbaum,

Eliot, M., \& Cornell, D. G. (2009). Bullying in middle school as a function of insecure attachment and aggressive attitudes. School Psychology International, 30(2), 201-214.

Espelage, D., \& Swearer, S. M. (2003). Research on school bullying and victimization: What have we learned and where do we go from here? School Psychology Review, 32, 365-383.

Fagot, B. I., \& Kavanagh, K. (1990). The prediction of antisocial behavior from avoidant attachment classifications. Child Development, 61, 864-873.

Feeney, J., \& Noller, P. (1996). Adult attachment. London: Sage Ltd.

Gini, G., \& Pozzoli, T. (2009). Association between bullying and psychosomatic problems: A meta-analysis. Pediartics, 123(3), $1059-1065$.

Glover, D., Gough, G., Johnson, M., \& Cartwright, N. (2000). Bullying in 25 secondary schools: Incidence, impact and intervention. Educational Research, 42(2), 141-156.

Grossmann, K. E., \& Grossmann, K. (1991). Attachment quality as an organizer of emotional and behavioral responses in a longitudinal perspective. In C. M. Parkers, J. Stevenson-Hinde, \& P. Marris (Eds.), Attachment across the life cycle (pp. 93-114). London: Travistock/Routledge.

Hazan, C., \& Shaver, P. (1987). Romantic love conceptualized as an attachment process. Journal of Personality and Social Psychology, 52(3), 511-524.

Hendrick, C., \& Hendrick, S. (1989). Research on love: Does it measure up? Journal of Personality and Social Psychology, 56, 784-794.

Ireland, J. L., \& Power, C. L. (2004). Attachment, emotional loneliness, and bullying behaviour: A study of adult and young offenders. Aggressive Behavior, 30, 298-312.

Kõiv, K. (2009). Bullying among Estonian pupils: An overview. In J. Mikk, M. Veisson, \& P. Luik (Eds.), Teenagers in Estonia: Values and behavior. Estonian studies in education (pp. 103-123). Frankfurt am Main Berlin Bern Bruxelles New York Oxford Wien: Peter Lang Europäischer Verlag der Wissenschaften.

Main, M., \& Cassidy, J. (1988). Categories of response to reunion with the parent at age six: Predicted from infant attachment classifications and stable over a one-month period. Developmental Psychology, 24, 415-426.

Marini, Z. A., Dane, A. V., Bosacki, S. L., \& Ylc-Cura. (2006). Direct and indirect bully-victims: Differential psychosocial risk factors associated with adolescents involved in bullying and victimization. Aggressive Behavior, 32, 551-569.

Monks, C. P., Smith, P. K., \& Swettenham, J. (2005). The psychological correlates of peer victimization in preschool: Social cognitive skills, executive function and attachment profiles. Aggressive Behavior, 31, 571-588.

Olweus, D. (1999). Sweden. In P. K. Smith, Y. Morita, J. Junger-Tas, D. Olweus, R. Catalano, \& P. Slee (Eds.), The nature of school bullying: A cross-national perspective (pp. 7-27). New York: Routledges.

Perry, D. G., Kusel, S. J., \& Perry, L. C. (1988). Victims of peer aggression. Developmental Psychology, 24(6), 807-814.

Renken, B., Egeland, B., Marvinney, D., Mangelsdorf, S., \& Sroufe, L. A. (1989). Early childhood antecedents of aggression and passive-withdrawal in early elementary school. Journal of Personality, 57, 257-281.

Rigby, K. (2003). Consequences of bullying in schools. Canadian Journal of Psychiatry, 48(9), 583-590.

Shaver, P., Collins, N. L., \& Clark, C. (1996). Attachment theory and internal working models of self and relationship partners. In G. Fletcher, \& J. Fitness (Eds.), Knowledge Structures in close relationships: A social psychological approach (pp. 25-61). Hillsdale, N. J.: Erlbaum.

Simpson, J. A. (1990). Influence of attachment styles on romantic relationships. Journal of Personality and Social Psychology, 59(5), 971-980.

Smith, P. K., \& Brain, P. (2000). Bullying in schools: Lessons from two decades of research. Aggressive Behavior, 26, 1-9.

Smith, P. K., Morita, Y., Junger-Tas, J., Olweus, D., Catalano, R., \& Slee, P. (Eds.) (1999), The nature of school bullying: A cross-national perspective. London and New York: Routledge.

Smith, P. K., \& Myron-Wilson, R. (1998). Parenting and school bullying. Clinical Child Psychology \& Psychiatry, 3, $405-417$.

Troy, M., \& Sroufe, L. A. (1987). Victimization among preschoolers: Role of attachment relationship history. Journal of the American Academy of Child and Adolescent Psychiatry, 26, 166-172.

van Ijzendoorn, M. H. (1997). Attachment, emergent morality and aggression: Towards a developmental socio-emotional model of antisocial behavior. International Journal of Behavioral Development, 21(4), 703-727.

Walden, L. M., \& Beran, T. N. (2010). Attachment quality and bullying behavior in school-aged youth. Canadian Journal of School Psychology, 25(1), 5-18. 